IRA-International Journal of Education \& Multidisciplinary Studies

ISSN 2455-2526; Vol.08, Issue 01 (July 2017)

Pg. no. 17-23

Institute of Research Advances

http://research-advances.org/index.php/IJEMS

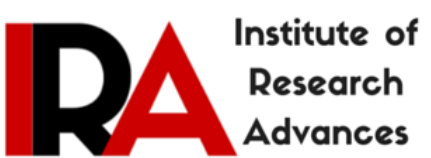

\title{
Influence of Divorce on Academic Performance of Female Scholars in Masvingo High Schools and Colleges, Zimbabwe
}

\author{
Lilian Manwa \\ Lecturer, Great Zimbabwe University, Zimbabwe.
}

Type of Review: Peer Reviewed.

DOI: http://dx.doi.org/10.21013/jems.v8.n1.p3

\section{How to cite this paper:}

Manwa, L. (2017). Influence of Divorce on Academic Performance of Female Scholars in Masvingo High Schools and Colleges, Zimbabwe. IRA International Journal of Education and Multidisciplinary Studies (ISSN 2455-2526), 8(1), 17-23. doi:http://dx.doi.org/10.21013/jems.v8.n1.p3

(C) Institute of Research Advances.

\section{(cc) BY-NO}

This work is licensed under a Creative Commons Attribution-Non Commercial 4.0 International License subject to proper citation to the publication source of the work.

Disclaimer: The scholarly papers as reviewed and published by the Institute of Research Advances (IRA) are the views and opinions of their respective authors and are not the views or opinions of the IRA. The IRA disclaims of any harm or loss caused due to the published content to any party.

Institute of Research Advances is an institutional publisher member of Publishers Inter Linking Association Inc. (PILA-CrossRef), USA. The institute is an institutional signatory to the Budapest Open Access Initiative, Hungary advocating the open access of scientific and scholarly knowledge. The Institute is a registered content provider under Open Access Initiative Protocol for Metadata Harvesting (OAI-PMH).

The journal is indexed \& included in WorldCat Discovery Service (USA), CrossRef Metadata Search (USA), WorldCat (USA), OCLC (USA), Open J-Gate (India), EZB (Germany) Scilit (Switzerland), Airiti (China), Bielefeld Academic Search Engine (BASE) of Bielefeld University, Germany, PKP Index of Simon Fraser University, Canada. 


\begin{abstract}
The aim of this study was to establish the influence of divorce on academic performance of female scholars in Masvingo High Schools and Colleges, Zimbabwe. This interpretive inquiry involved a descriptive survey in order to find out the influence of divorce on the academic performance of female students. In-depth interviews and open-ended questionnaires were used to collect data from forty participants from ten high schools and two colleges. A sample of forty participants was purposively selected from all the institutions. Early teen marriages were established as one of the major causes of divorce as young brides and grooms fail to understand the level of commitment they are expected of. Drug abuse, infidelity, lack of communication, poverty and migration were the factors that caused divorce. The study revealed that divorce like death causes grief and pain to the people involved especially females. It was noted that it is one of the major causes of stress and negatively impacts on academic performance of female scholars. The findings also revealed that most of the study time is spend trying to solve or adjust to the new life style. The study recommends that both the international and national communities to seriously look into the effects of divorce on scholars with the aim of trying to reduce the rate of divorce and its effects on people involved. Legislations that are pro women should be in place as they also severely punish culprits who recklessly break their marriages.
\end{abstract}

Key words: divorce, scholars, academic performance, family, marriage.

Divorce in Zimbabwe like any other nations has affected directly or indirectly all people across the globe. It has become one of the several types of family problems that severely affect all the people involved and has become a global concern that is gaining more prominence (Galluzo, 2012; Cherlin, 2008; Crawford, 2006). Traditionally the family was known to be the first and most important institution where children develop physically, emotionally, spiritually, educationally and morally. Chireshe (2012) asserts that the family is highly valued in the Zimbabwean culture. Research has found out that broken families are inevitable and their impact on people involved is enormous (Ahrons, 2004; Amato, 2003). Divorce in the contemporary world is dynamic and is now affecting the young couples as never before (Palen, 2001). The worst affected group is the school going age which is the focus of this study on high schools and college scholars. For the college scholars some may come to college married and then end up in divorce. William (2002) suggests that parental divorce hurts female high school students more than it hurts their male peers.

During the primitive days in Africa and Zimbabwe in particular marriage was mainly for the mature except in cases of a son in-law working for the in-laws in exchange of their daughter (kutema ugariri in Shona), virgin pledging (kuripa ngozi in Shona) and widower/widow inheritance (chimutsamapfiwa/kugara nhaka in Shona respectively) which were used to solve family problems. Mawere and Rambe (2011) posit that in some ethnic groups in Zimbabwe the mentioned cultural practices are still prevailing. Marriage was also by local family to family arrangement. The fact that the family was to approve the in laws was a measure to minimize divorce and separation. Factors which were considered were the life history of the family including the social status. Contrary to the primitive marriages, most young people get into marriages very early and without the consent of their parents which may be the reason of high rate of divorce. According to Wallerstein and Lewis (2004) half of the marriages in United States of America ended in divorce for the past three decades and the cases of divorce are rising sharply. This implies that the sudden rise has predisposing factors such as early teen marriages.

In most ethnic groups in Zimbabwe a son marries a wife for the whole family for example a woman will respect the brother and sisters of the husband as she does to her own husband. Some religious groups support this practice despite that it is very stressful to the bride basing on a bible verse (Ephesians 5 verse 22-23) which reinforces the subservient role of women. The relationships mainly affect females because they are the ones who join the husband's family. Problems between spouses were handled by both families and most of the problems were solved by aunts and uncles. Crawford (2006) states that in the traditional society marriages that was arranged by the family were lasting and more stable as compared to those arranged in this modern era. The introduction of western culture and education has caused some changes in African family structures. Migration to towns and cities also changed the neighborhood relationships. Acculturation has caused changes in both men and women's attitudes towards marriage (Loweistein, 2009). All these changes mentioned above have a major impact on stability of marriages. In Zimbabwe the rate of divorces rose to alarming rates during the era when the South African gold mines (Wenera in Shona) 
were employing males from all the countries within the southern region and most females were left alone by their husbands some who never returned home.

In Zimbabwe, during the colonial era there was a Chimurenga war which was experienced by most people and also worsened the situation as young females were taken to be sexually abused by freedom fighters and the army. The young females were forced to marry early in-order to runaway from the catastrophe of war. Marriage became a means of protecting the young females from sexual abuse. This scenario marked the beginning of a new era where divorce was common among young adults as most marriages were not based on love but for convenience. The affected females who failed to secure a good marriage ended up in divorce and those females affected by divorce were encouraged to return to school. After independence the policies which prohibited single and married women to get back to school were reversed and education was for all. Such a move encouraged people in marriage to go to school. The policy was well accepted however, there were some negative effects which led to family disintegration as some females were carried away and divorce their husbands or vice versa. Some marriages were broken due to promiscuity by either or both spouses. Chobarkar (2011) asserts that promiscuity and polygamy are also major causes of divorce.

Divorce rate has generally risen in a very alarming rate and increased sharply from the early $20^{\text {th }}$ century in most countries (Cherlin, 2008). Divorce as a problem was of ancient times an experience which was rare and mostly for the adults (Crawford, 2006). The modern world is dynamic and divorce is now affecting both the young and old (Palen, 2001). This implies that divorce has become a great challenge to most nations. The high prevalence of early teen marriages in Zimbabwe has also seen to be influencing the high rate of divorce which affects scholars. Children marrying children or a child marrying a very old person may lead to divorce due to immaturity or generation gap respectively. Teen scholars and those who are in pre-adulthood stage may also be involved in divorce and this may have a negative impact on academic performance. Effects of divorce may be very challenging as divorce in the Zimbabwean context is not just between the two but between families and in some cases the clan members. Reichman (2004) affirms that poor health of a spouse or a child may cause divorce. Loweinstein (2009) posits that persistent challenges such as miscarriages and death of a child or children may lead to divorce. Children are also affected by divorce especially when they are still young and also teenagers in high schools may be affected by divorce as they may witness their own divorce and that of their parents.

Family disintegration and its negative effects on families is a cause for concern for most governments in the world (Cherlin, 2008). Nair and Murray (2005) established that divorce affects the children involved in divorce in three major ways such as that the other parent is absent, adjustment to a new living situation and conflict among the parents. During the ancient times divorce was unheard of since the consequences were quiet severe to the one who was found guilty. In the traditional Zimbabwe, divorce was not an easy task as the process of remarrying was also difficult when one has a bad record of divorce since marriages were locally arranged. It seems these modern days divorce is very fashionable as an individual marries and remarries several times without facing difficulties in most cases as the distances may help in disguising one's character. Some individuals may support (maintaining) more than one child with different mothers for example, the two ladies maybe staying in different towns or countries.

The trauma involved in the process of divorce causes absenteeism as in some cases involve courts in trying to settle the issue of the custody of children. Stress was recently established as one of the major killer as it triggers a number of ailments. Stress, headache and muscle pain are the major effects of stress that inhibit proper concentration during lessons (Manwa, 2010, Nair \& Murray, 2005). Conditions such as high blood pressure may cause an erratic attendance for the scholar. Pressure from peers and educational demands may also worsen the situation and may cause poor academic performance. Women are the most vulnerable group and stress is exacting its toll on them (Manwa, 2010; Larson \& Simonis, 2005; Burk \& Speed, 1995). The level of stress which is endured by the affected partner may vary due to the background of the marriage. However, stress inevitably affects ones' concentration during lessons or study time. The psychological damage due to divorce builds before the divorce and dissipates after it affects the academic progress and continues to weaken it (USA Today, 2002). Emery (2004) and Hetherington and Kelly (2002) say that students who are experiencing divorce may also face financial constraints if they depend on the spouse or if the parents divorce and the breadwinner cease to provide the financial support required.

Wallerstein, Lewis and Blakslee (2000) state that divorce significantly causes financial constraints to the broken family. Failure to procure required school consumables and other upkeep needs negatively affect good academic performance. Dropping out of school due to financial problems and rejoining school or college affects students as they are normally older than their counterparts. This lowers the self-esteem of the students as they see their young 
ones excelling. Self-confidence is critical in achieving good performance (Manwa, 2014). Divorce may lead to migration and for the high school pupils may lead to a change in school and teachers. This normally affects the academic performance of those in examination classes who need to write public examinations. The change of environment by the pupil may take him or her time to adjust and then fail to perform well academically. In the case of students they may change the place to stay and this may cause adjustment problems that may lead to poor academic performance (Manwa, 2014; Collins, Jordan \& Coleman, 2010).

Ahrons (2007) the effects of divorce on scholars calls for interventions which seeks to reduce the prevalence of divorce. The adverse effects of divorce have left most children suffering especially the scholars hence, the need for the government and the international community as a whole to assist in reducing the rate of divorce. Consequences of divorce if put in place may inhibit easy divorce as the wrong doers are severely punished. There is need for laws that make divorce a difficult task to achieve. Some females may fall prey of married people who just give them children but fail to marry them. The effects are similar to those of divorce hence the need to be very harsh to those who commit adultery and have children outside marriages.

\section{Methodology}

The current study sought to find out the influence of divorce on academic performance. This qualitative approach was used since the consequences of divorce involve feelings and emotions of individuals. Gray (2009) and Denscombe (2007) state that the study of human behaviour is best done qualitatively since it deals with feelings and emotions of people. This study used a descriptive survey in order to collect soft data from the participants. A descriptive survey design examines a relatively large population and probes deeply and analyses interaction between factors (Best \& Khan, 2006; Neuman, 2006; Sidhu, 2003). The descriptive survey was used as a mapping strategy of collecting a detailed data on the influence of divorce on academic performance. Patton (2002) emphasises that an important characteristic of a descriptive survey is that the study focuses on real world situations as they unfold naturally.

In-depth interviews and open-ended questionnaires were used to collect data from forty participants. The in-depth interview or a conversation with a purpose was the best tool used to solicit data from the all the participants since it allowed person to person discussion in a natural manner (Best \& Khan 2006; Boyce \& Nealev 2006; Neuman, 2006). The open-ended questionnaires were used for their advantage of privacy and some detailed answers. According to Reja, Manfreda, Hlebec, and Vehovar1 (2003) there are two quite different reasons for using openended such as that they can be used to discover the responses that individuals give spontaneously and also to avoid the bias that may result from suggesting responses to individuals.

The sample was purposively drawn from a population of over one thousand pupils from ten high schools and two colleges in the district. Sidhu (2003) suggests that the nature of the sample requires a careful selection so that it represents the population. Neuman (2006:222) suggests that purposive sampling is appropriate to select unique cases that are especially informative. Five college students from each institution and three students from each high school were conveniently sampled to make a total of forty participants. In-depth interviews were conducted with the college students and open ended questionnaires were given to the thirty high school pupils. The reason for using in-depth interviews with college students was because the students who were chosen had experienced divorce as individuals or their parents may have divorced. Very few high school pupils who were involved in answering open ended questions were directly involved in divorce but most of the high school pupils experienced divorce of parents.

\section{Data presentation, analysis and discussion}

Collected data were presented in narrative forms and analyzed thematically according to the research objectives.

\section{Causes of Divorce}

The current study revealed that early teen marriage is one of the major causes of divorce among the high school college scholars. A survey in India established that girls who marry before nineteen years are reported to experience domestic violence because of immaturity (UNICEF, 2008). They usually make decisions which lack wisdom because of the age. Westport (2008) suggests that teens in marriage succumb to demands of marriage. The young brides are in most cases stereotyped as inferior to men and are expected take their subservient role and obey their husbands without question. Gender inequalities and bias in marriages influence the rate of divorce among young couples (Manwa, 2014). Most of the students who experienced divorce were complaining of abuse and also were blaming themselves and their spouses for wrong decisions and judgements which were a result of immaturity. 
Poverty was cited by most scholars other as major causes of divorce in young couples. Female students who have endured persistent poverty are usually seduced from their husbands as they are attracted by wealthy of other man. Experience of most participants was that quarrels were more frequent in broken families where resources were scarce and usually family members fight for the mean resources. Husbands and wives may divorce due to repeated quarrels related to lack of resources. Relationships within families can be strained as people fail to share equitably the available meager resources.

The change in life styles as people are affected by acculturation, media and technology was cited by all participants as one of the causes of divorce. In Zimbabwe marriage was rated as sacred and was a family issue. Marriage was not meant for the two but for the whole family and clan. In modern days two individuals may stay together without the concern of the two families. This has result in divorce as marrying and remarrying is common among the young people. Lowenstein (2009) posits that traditionally, separation or divorce was between the families and not only the two parties. The dissolution of marriage called for both families to sit down and try to save the marriage except when it was beyond their control. Issues related to drug abuse and abuse of finances is some of the causes of divorce mentioned by most participants. It is common knowledge that drug abuse is associated with domestic violence and risk of divorce. Heavy drinking is also linked to overspending on alcoholic beverages. In Zimbabwe, alcohol is more expensive than the ordinary beverages. This may imply that too much alcohol intake reduces the disposable income of the family and hinders progress. There is a great association between healthy behaviour and risk of divorce (Goldman, 2000).

Lowenstein (2009) posits that partners who do not resemble each other with respect of age, educational level, religion, ethnic background, social origin and occupational status led to higher divorce rate. Jonsen et al. (2000) suggest that models of hetorogenny with regard to age, religion and educational attainment have the greatest influence on divorce. Communication in marriage is also heavily influenced by age and educational differences and this may also lead to divorce. Generation and educational gap may cause opposive thinking and behaviour that do not resemble each other and causes communication breakdown between spouses. Good communication between spouses enhances emotional intimacy between the two. Married women especially the young generation feels neglected when there is less or no mutual communication from their husbands. One of the participants mentioned that she is usually emotionally hurt when her husband ignores her.

\section{Influence of divorce on academic performance}

All the female students who participated in this study revealed that divorce whether indirectly or directly really negatively affect academic performance. This finding from the current study is persistent with Galluzzo (2012) who found out that divorce negatively impact the academic performance of scholars especially females. One of the scholars mentioned that one's family is the source of support and disintegration of that basic institution is a disaster to someone who is required to pay attention during lessons or lectures. The family when in good shape provides both physiological and emotional needs. Divorce was like death that causes grief which ranges from mild to severe. Most students submitted that whether it is divorce of parents or if they are directly involved it causes pain and stress. Most researches have established that divorce is one of the major causes of stress among scholars (Nair \& Murray, 2005; Wallerstein \& Lewis, 2004; Herrington \& Kelly, 2002). The Zimbabwean culture encourages women to endue and preserve their marriages. This belief is supported by the bible (Christian religion) stipulates that a wise woman builds her home while a foolish one destroys it by her hands (Proverbs 14 verse 1). This implies that women are in most cases the recipients of divorce and suffer more. Some participants were giving examples of other students who divorced their husbands and were said to be suffering. It seems that the culture of Zimbabwe do not sympathize with women who divorce their husbands for trivial or no genuine reasons. One participant said that most spouses who divorce their partners unjustly will in the end suffer as they may continue with the habit of marrying and divorcing.

The issue of the custody of children in a family with children is a source of stress to the mother. Nair and Murray (2005) posit that divorce results in one parent taking care of children and females are the most affected and suffer as they carry the burden of child rearing. Female students who were divorced and have the custody of children due to age have indicated that combining school and being a single divorced parent is an unbearable burden. Most husbands tend to take care of their new spouses and their children if any and neglect their own children. Time in this case will be divided and then negatively affect academic performance. One student who was divorced narrated a sad story of failing some courses as she was going through divorce and trying to settle down and take care of the children as a single parent. Young children are more burdensome as they will want their father who is in most cases nowhere to be found. 
Single parenting is regarded to be one of the most challenging careers for both males and females especially when not financially empowered. In the case of divorced parents one high school student who experienced the divorce said that the nasty words and arguments are still echoing in her ears. This has caused her to perform badly as she was attending to her own and her mother's grief. Wallerstein et al. (2000) assert that the effects of divorce may last for life depending on the gravity of the pain caused. Grieving causes the mind to mix up issues and have a short listening spun. Denial of the misfortune was mentioned as one of the cause of poor academic performance. Failing to come into terms and mapping a way forward maybe too long to the extent that it negatively impacts on academic performance. Wrong decisions which are effected after divorce, such as, getting into another marriage soon after divorce were cited as another cause of poor academic performance. One student who had a friend who tried to revenge by having another marriage soon after divorce was said to be having adjustment problems which are costing her good performance.

Most female scholars who were divorced indicated that they suffered emotionally and physically. Stress, anxiety and depression when not handled properly may result in sicknesses such as high blood pressure, illness, and stress headache and digestion complications (Manwa, 2010; Larson \& Simonis, 2005; Emery, 2004). Illnesses are retrogressive in all things including academic performance. Grief after divorce can lead to such conditions and some female scholars who affected by divorce were mentioned to be hospitalized due to stress. Hospitalization may be expensive and that may result in further stress if resources are not available. Some lecturers who were involved in counselling some of the students established that grief may need clinical therapy where drugs may be used. This finding is persistent with Hetherington and Kerry's (2002) finding that divorce is expansive and significantly reduces progress.

Most participants were submitting suggestions they thought were helpful in reducing the high rate of divorce. One school head suggested that Zimbabweans should revert to their extended families. Extended families were given prominence in Zimbabwe as each member would be involved in the affairs of every family member. Extended families were encouraging accountability since each member was responsible to his/her actions. Acculturation was blamed for the changes in marriages as most people are copying what they see in movies. The other teachers were advocating the need to repair the cultural fabric of the nation as strict adherence to good moral values is taught and emphasised in schools and colleges (unhu/ubuntu in Shona/Ndebele respectively). Some were indicating that since the damage has already been done in some cases, parenting skills which focus on single parents is critical in order to reduce further recur or replica of divorce in such families.

\section{Conclusion and Recommendations}

The study revealed that the issues of divorce negatively impact an academic performance of female students. Divorce like death is a source of grief, anxiety, stress and depression. All the mentioned effects affect the emotional and physiological status of the scholar which results in the mind which is ready to assimilate and digest concepts to be studied. The study recommend that guidance and counselling be given the importance it deserve as it important to get immediate counselling after experiencing divorce since they need to revel to their maiden name and go through humiliating changes. It is recommended that new laws should be put in place which allows women to retain the husband name if they wish to do so rather than being forced to change the surname to their maiden after such a nasty experience. Schools, colleges and universities should have specialised guidance and counselling officers who have offices that work with the students on daily basis. Guidance in how to study effective when under stress is needed in form of mono graphs and pamphlets.

\section{References}

1. Ahrons, C. (2004). Were Still Family: What Crown Children have to say About their Parent's Divorce. New York: Harper Collins.

2. Amato, P.R. (2001). Children's Adjustment to Divorce. Theories, Hypothesis and Emperical Support. Journal of Marriage and the Family. Vol 55. 23-28.

3. Best, J. W. \& Kahn, J, V. (2006). Research for Education. Boston Library of Congress Colloguing-inPublication Data.

4. Boyce, C. \& Neale, P. (2006). Conducting in-depth interviews: A guide for designing and conducting indepth interviews for evaluation input. USA: Pathfinder International. http://www2.pathfinder.org/site/DocServer/m_e_tool_series_indepth_interviews.pdf (Downloaded July 2012).

5. Burk, C. \& Speed, B. (1995). Gender, Power and Relationships. London: Routeledge. College Publishers. 
6. Cherlin, L. J. (2008). Public and Private Families. $5^{\text {th }}$ Edition. New York: McGraw Hill.

7. Chireshe, E. (2012). The utility of the Zimbabwean Domestic Violence act: Christian and Muslim Women's Experiences. PhD Thesis: University of South Africa (UNISA).

8. Chobharka, R. (2011). www.buzzle.com/articles/cause-and-effectstaofdivorce.html

9. Collins, D., Jordan, C. and Coleman, H. (2010). An Introduction to Family Social Work $3^{\text {rd }}$ Edition, United States: Brooks Cole Cengage.

10. Crawford, M. (2006). Transformations: Women, Gender and Psychology. New York: McGraw Hill Companies.

11. Denscombe, M. (2007). The good research guide for small scale social research projects. Maidenhead, Berkshire: McGraw-Hill Open University Press.

12. Emery, RE. (2004). The Truth About Children and Divorce: Dealing With Emotions So You and your Children ca Thrive. New York: Viking Press.

13. Galluzo, DM. (2012). The Academic and Social Effect of Divorce on Early Childhood Students in Schools. North Eastern University; Boston, Massachusetts. Education Doctoral Thesis. IRIS. http://hdl.handle.net/2047/D20002769.

14. Gray, EG. (2009). Doing research in the real world. $2^{\text {nd }}$ Edition. London: Sage Publications.

15. Hetherington, E.M. \& Kelly, J. (2002). For Better for Worse, New York: Norton.

16. Larson, M.H. and Simonis, G.F. (2005). Relief from Stress. The Journal of Awake. 86 (3), 3-11.

17. Loweinstein, L. (2009). http://www.parentaalienationinfo/index.html.

18. Manwa, L. (2010). The causes and effects of stress on working women in Zimbabwe. Journal of History and Development 1(2): 26- 37.

19. Manwa, L. (2014). Determinants of Academic Performance of Female Students at a University in Masvingo Province, Zimbabwe. PhD Thesis. UNISA.

20. Marshall, C. and Rossman, G. B. (2008). Designing a Qualitative Research. London: Sage Publications.

21. Mawere, M. \& Rambe, P. (2012). Violation and Abuse of Women Rights in the Customry Practice of Kuzvarira Among the Ndau People. South Africa. University of Cape Town.

22. Nair, H. \& Murray, AD. (2005). Predictors of Attachment Security in Pre-school Children from intact and divorced families Journal of Genetic Psychology. Vol 166 (3) 245-264.

23. Neuman, w. L. (2000) Social Research Method: Qualitative and Qualitative Approaches. USA: Allyn and Bacon.

24. Palen, J.J. (2001). Social Problems for the Twenty First Century $1^{\text {st }}$ Edition. New York: McGraw Hill.

25. Patton, MQ. (2002). Qualitative research and evaluation methods. $3^{\text {rd }}$ Edition. New York: Sage Publications.

26. Reichman, N. (2004). Unconventional Wisdom Fatherhood. New Jersey: Robert Wood Johnson Medical School.

27. Sidhu, K.S. (2003). Methodology of Research in Education. New Delhi: Sterling Publishers Pvt. Ltd.

28. UNICEF. (2008). Child Marriage: A childhood and the Legislation Reform Initiative Paper Series. New York.

29. US Today. (2002). Children of Divorce: Educational Achievements. http://www.divorcereform.org/.

30. Wallerstein, JS. \& Lewis, JM. (2004). The unexpected Legacy of Divorce. Report of a 25-year study. Psychoanalytic Psychology. 21 (3) 363-370.

31. Wallerstein, JS., Lewis, JM. \& Blakeslee, S. (2000). The Unexpected Legacy of Divorce; A 25-year Landmark Study. New York: Hyperion.

32. William H. J. (2002). Examining the Effects of Parental Absence on the Academic Achievement of Adolescents: The Challenge of Controlling for Family Income Journal of Family and Economic. Issues Vol. 23, Num. 2, Summer 2002, pp.189-210 Journal website: http://www.wkap.nl/prod/j/1058-0476 